\title{
Borderline-tuberculoid leprosy: clinical and immunological heterogeneity
}

\author{
M. I. F. PIMENTEL*, E. P. SAMPAIO, \\ J. A. C. NERY, M. E. N. GALLO, M. H. F. SAAD, \\ A. M. MACHADO, N. C. DUPPRE \& \\ E. N. SARNO† \\ Leprosy Laboratory, Oswaldo Cruz Institute, FIOCRUZ, Avenida \\ Brasil, 4365 - Manguinhos, CEP 21045-900, Rio de Janeiro, RJ, \\ Brasil; *Dermatology Service, HUCFF, Federal University of Rio \\ de Janeiro, Ilha do Fundão - Rio de Janeiro, RJ, Brasil
}

\section{Accepted for publication 25 June 1996}

Summary The authors analysed some immunological criteria in leprosy patients diagnosed as borderline tuberculoid by the presentation of different grades of skin lesions as well as different grades of nerve involvement. Only $50 \%$ of the patients presented a single skin lesion and $58 \%$ had none or only one affected nerve. Nineteen patients $(39 \cdot 6 \%)$ showed a positive lepromin reaction (induration $\geq 5 \mathrm{~mm}$ ).

Patients with a positive skin test had a greater number of skin lesions when compared with patients with a negative lepromin test. Fifty-seven percent of the patients were found to be positive using a lymphoproliferation test (LTT) in response to Mycobacterium leprae antigens. Positive LTT results did not correlate with the number of skin lesions, but patients unresponsive to LTT had a lesser extent of nerve involvement. Four out of 18 patients $(22 \%)$ released high IFN $\gamma$ levels in PBMC culture stimulated by $M$. leprae. (mean $\mathrm{U} / \mathrm{ml} \pm \mathrm{SD}=142 \pm 72$ ). All of these 4 patients presented only one skin lesion, although three of them had more than one affected nerve.

Nineteen out of 21 patients $(90 \cdot 5 \%)$ showed no anti-PGL- 1 antibodies in their serum. The low levels of anti-PGL-1 antibodies among these patients confirmed their tuberculoid background even in those with multiple skin lesions.

These findings seem to attribute an important role to IFN $\gamma$ in restraining the spreading of the infection in the skin, but IFN $\gamma$ may have an opposite effect on the nerves. The potential pathological effects of IFN $\gamma$ during the delayed type of hypersensitivity can be related to its ability to synergise with other inflammatory cytokines such as TNF $\alpha$, IL-1 $\beta$, and others.

†Correspondence to: Leprosy Unit, Oswaldo Cruz Foundation, Avenida Brasil, 4365 - Manguinhos, 21045-900 - Rio de Janeiro - RJ, Brasil 


\section{Introduction}

Leprosy is a chronic infectious disease that affects skin and peripheral nerves. The clinical spectrum in leprosy seems to correlate with the host immune response. ${ }^{1}$ T-celldependent immunity to Mycobacterium leprae is high in healthy-exposed individuals and in tuberculoid leprosy patients with localized disease, but is strikingly absent in lepromatous leprosy patients who have a high bacillary load and widely disseminated lesions. Thus, cell-mediated immunity (CMI) protects against dissemination of bacteria and disease. It has recently been hypothesized that the spectrum of leprosy reflects the balance between $\mathrm{T}$-helper-cell populations (Th1 and Th2 CD4+ T cells). ${ }^{10}$ Indeed, analysis of mRNA expression in tissue samples of leprosy patients through RT-PCR showed two distinct lymphokine patterns. ${ }^{12}$ Tuberculoid lesions were characterized by prominent expression of IL- 2 and IFN $\gamma$ mRNA, a Thl pattern associated with cellmediated immunity. Moreover, lepromatous lesions primarily expressed IL-4, IL-5 and IL-10 mRNA, the Th2 pattern which favours humoral immunity and supression of DTH.

IFN $\gamma$, a product of activated $\mathrm{T}$ lymphocytes, has been considered the major mediator at the effector end of the immune response. ${ }^{8}$ Its production correlates with the ability of mononuclear phagocytes to kill microorganisms. It was also demonstrated that household contacts of lepromatous patients who were unable to secrete IFN $\gamma$ upon specific in vitro stimulation had a higher risk of developing leprosy as compared to high responders. ${ }^{14}$ Tuberculoid leprosy patients (TT, BT) are known to respond in vitro to $M$. leprae antigens, although nonresponder BT patients have also been reported. ${ }^{15}$ However, the in vitro immunological status of paucibacillary patients and its correlation to their clinical activity, lepromin response, and the occurrence of relapse has not yet been investigated. Nerve lesions and the extent of body area affected are important parameters in determining the treatment of leprosy patients. ${ }^{3}$ The aim of this study was to correlate the in vitro and in vivo immunological responses of tuberculoid leprosy patients with the extension of skin lesions and the involvement of peripheral nerves.

\section{Material and methods}

PATIENT POPULATION

Leprosy patients from the Leprosy Out-Patient Unit, Oswaldo Cruz Foundation, Rio de Janeiro, Brazil, were diagnosed according to the Ridley-Jopling classification. ${ }^{11}$ A total of 48 borderline-tuberculoid (BT) leprosy patients (18 male and 30 females), 15 to 78 years of age (mean $\pm s d=41 \pm 12$ ), were studied. Patients were included in the World Health Organization (WHO) multidrug therapy (MDT) regime for paucibacillary patients. None of them had been previously treated. All of them received 6-monthly supervised doses of $600 \mathrm{mg}$ rifampin and daily self-administered doses of dapsone $100 \mathrm{mg} /$ day. At diagnosis, dermatological and neurological examination was performed on all patients. Number and characteristics of cutaneous lesions were noted. Peripheral nerves were assessed through palpation of the main nerve trunks and corresponding pain and/or thickness, when found, was noted. Sensory and voluntary muscle evaluation was done in all patients using simple techniques and Semmes-Weinstein monofilaments, by trained personnel. Patients were assessed monthly during treatment by way of 
dermatoneurological examinations. The immunological tests were performed following patients' consent for blood collection at diagnosis. Six patients (12.5\%) presented reactional episodes (either reversal reaction ( $R R$ ) or neuritis), 3 during multidrug treatment, and 3 during the surveillance period. Reactional lesions were biopsied to confirm clinical diagnosis of a reactional state.

ENUMERATION OF BACILLI

Slit smears for bacterial index (BI) determination taken from three sites (both earlobes and a cutaneous lesion) were performed at the time of diagnosis, as a routine procedure. All 48 patients were BI negative.

\section{ANTIGEN}

Skin tests were done with lepromin A, Carville, USA (provided by WHO). For in vitro tests, armadillo-derived sonicated $M$. leprae antigen was provided by Dr R. J. W. Rees (IMMLEP Bank, The National Institute of Medical Research, Mill Hill, England). Optimal antigen stimulating concentration was found to be $20 \mu \mathrm{g} / \mathrm{ml}$.

\section{LYMPHOCYTE TRANSFORMATION TEST (LTT)}

Heparinized venous blood was collected for in vitro tests and peripheral blood mononuclear cells (PBMC) were isolated by Ficoll-hypaque (Pharmacia Fine Chemicals, Piscataway, NJ, USA) density centrifugation. PBMC were incubated in triplicate at $2 \times 10^{5}$ cells/well at $37^{\circ} \mathrm{C}$ in 96 -well U-bottom plates (Costar Corporation, Cambridge, MA, USA) in $200 \mu \mathrm{l}$ RPMI 1640 medium (Gibco Laboratories, Grand Island, NY, USA), supplemented with $10 \%$ pooled AB serum, $100 \mathrm{U} / \mathrm{ml}$ penicillin, $100 \mu \mathrm{g} / \mathrm{ml}$ streptomycin and $2 \mathrm{mM}$ L-glutamine (Gibco Laboratories). Cells were cultured for 5 days in the presence or absence of antigen, when supernatant was collected for determination of cytokine production. The remaining cells were pulsed with $1 \mu \mathrm{Ci}$ of ${ }^{3} \mathrm{H}$-thymidine for another $18 \mathrm{hr}$. Results obtained as counts per minute (cpm) are expressed as stimulation index (SI, cpm obtained from stimulated cultures/cpm obtained in control cultures).

\section{INTERFERON-GAMMA (IFN $\gamma$ ) PRODUCTION}

The amount of IFN $\gamma$ on a 5-day culture supernatant was assayed using a commercial RIA kit (IMRX Corp., Centocor Malvern, PA), specific for the active human IFN $\gamma$ as described. ${ }^{15}$ Levels of IFN $\gamma$ are expressed as Units $/ \mathrm{ml}(\mathrm{U} / \mathrm{ml})$ in stimulated cultures minus $\mathrm{U} / \mathrm{ml}$ obtained in control cultures. The cut-off point for positive response was $40 \mathrm{U} / \mathrm{ml}$, which is $4 \mathrm{sd}$ above mean values obtained in unstimulated cultures.

ELISA TEST FOR PGL-1

Serum samples from all tuberculoid patients were collected aseptically, processed under sterile conditions, and kept frozen $\left(-20^{\circ} \mathrm{C}\right)$ until use. The presence of specific $\operatorname{IgM}$ antibodies anti-ND-BSA (natural disaccharide conjugated to bovine serum albumin, 
which represents an immunodominant part of the phenolicglycolipid 1, PGL-1) in the serum was assayed in 21 patients as described. ${ }^{9}$ Plates were read in a Titertek Multiscan (Flow Laboratories), at $492 \mathrm{~nm}$, and the results expressed as optical density variation $(\Delta \mathrm{OD}=\mathrm{OD}$ obtained in the antigen coated wells minus the OD obtained in the control wells). A sample was considered positive when its OD exceeded by 2 sd the mean results obtained in the healthy control population. Cut-off OD value for positive response was $0 \cdot 27$.

\section{SKIN TEST}

Lepromin skin tests were performed by intradermal injection of $0.1 \mathrm{ml}$ of the standardized crude antigen preparation (lepromin A, 1.6 × $10^{8}$ bacilli/ml, National Hansen's Disease Center, Carville, LA, USA) in the volar surface of the left forearm. Readings were performed after 21-28 days and reactions $\geq 5 \mathrm{~mm}$ were considered positive (National Guide - Leprosy Control Program). All patients were lepromin tested before initiating specific leprosy treatment. All the injections and readings were done by the same trained person.

\section{SKIN BIOPSIES}

All patients underwent biopsies at the periphery of skin lesions before starting treatment. Biopsy specimens were processed and stained by hematoxilin and eosin, and by Wade method for acid-fast bacteria. Typical infiltrates of BT leprosy, as stated by Ridley \& Jopling classification system, ${ }^{11}$ were found in all 48 patients, as a prerequisite for inclusion in the study. None of the patients had acid-fast bacilli identifiable in biopsy specimens.

\section{STATISTICAL ANALYSIS}

Tests were used for statistical evaluation of significance. Chi-squared test, Correlation, Regression and Somer's Deviance were used when appropriate. Immunological tests were related to each other, and to skin lesions and nerve involvement. Standard deviation (sd) was used to express variance. Probability $(P)$ less than 0.05 in the statistical tests was considered statistically significant.

\section{Results}

\section{CLINICAL EVALUATION}

BT patients included in the study presented characteristics clinical lesions and typical epithelioid granulomas in skin lesions, but had no detectable acid-fast bacilli in skin smears. All patients were treated with the paucibacillary WHO regime, and none of them has presented clinical diagnosis of relapse (mean of 6 years of follow-up). Among the 48 BT patients studied, $24(50 \%)$ presented a single cutaneous lesion with well-defined borders, which were infiltrated in some patients, either anaesthetic or hypoaesthetic. The other patients presented $\geq 2$ cutaneous lesions and at least 5 patients $(10 \cdot 4 \%)$ presented 10 or more lesions. Concerning the number of affected nerves at the diagnosis, 28 


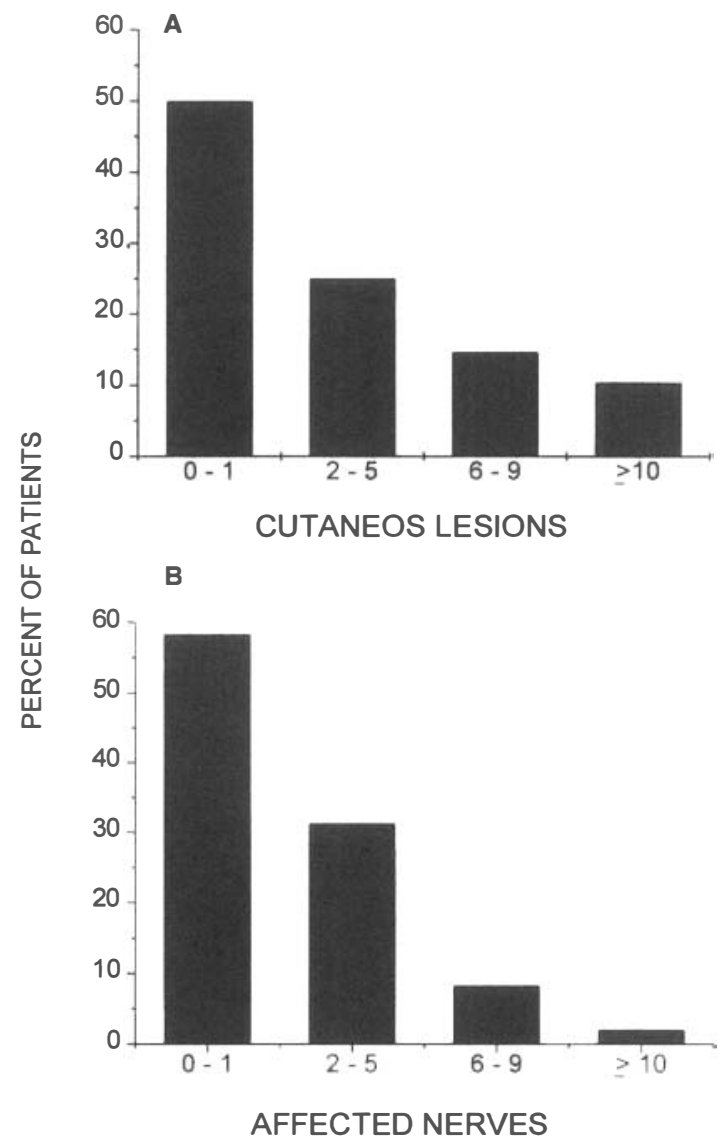

Figure 1. Distribution of the 48 BT patients according to the number of (A) cutaneous lesions, and the number of (B) affected nerves.

patients $(58 \cdot 3 \%)$ showed only one affected peripheral nerve or none at all. Of the other 20 patients, 19 had from 2 to 9 nerves that were damaged and only one patient $(2 \cdot 1 \%)$ had 10 affected nerves (Figure 1). Fifteen patients (53.6\%) among those with no affected nerves or only one showed a single cutaneous lesion, and 11 patients $(55 \%)$ with more than one affected nerve had also more than one lesion. However, no significative correlation was observed between the number of cutaneous lesions and the number of affected nerves.

IMMUNOLOGICAL TESTS

\section{Lepromin test}

Nineteen out of 48 patients tested $(39.6 \%)$ showed a positive lepromin reaction. Patients with positive lepromin tests had more skin lesions when compared to patients with negative lepromin tests (Figure 2). Although not statistically significant, it was noted that among the 19 patients positive for lepromin, 7 (36.8\%) presented a single skin lesion 


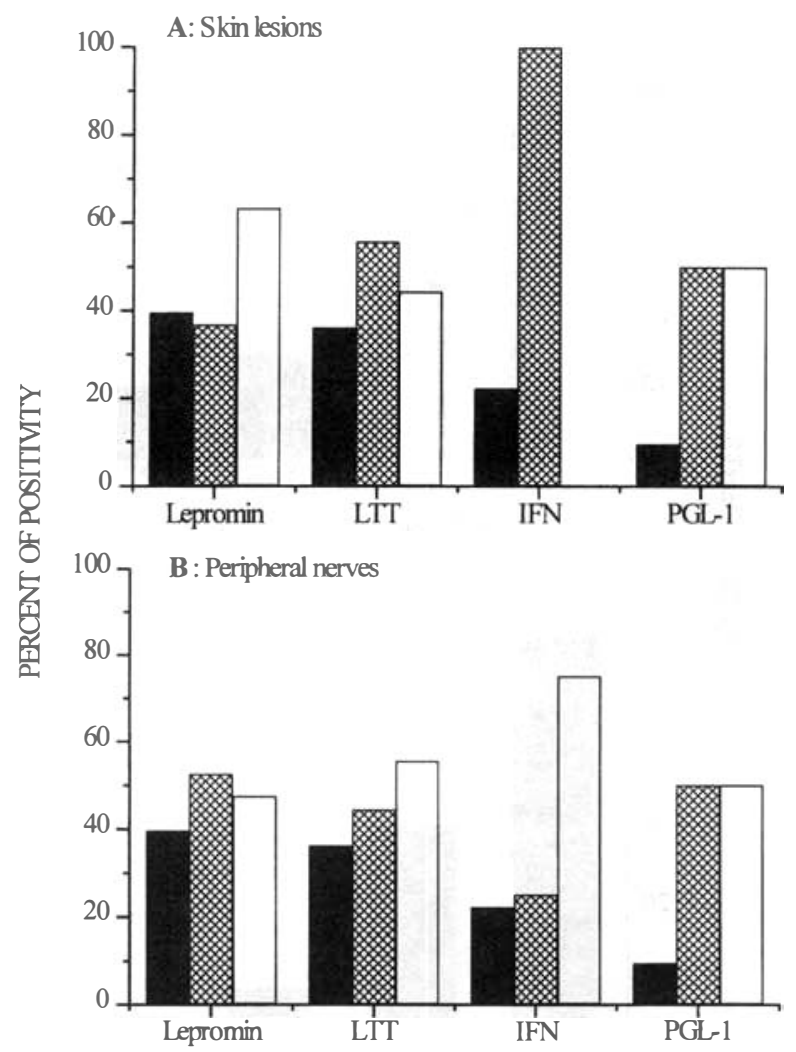

Figure 2. Relationship between the positivity of BT patients in the immunological tests and the extent of skin involvement, or the amount of affected peripheral nerves. Bars represent numbers of patients above cut-off in each immunological test. $\square$, total positive cases; 罒, single; or $\square$ multiple involvement. Cut-off values are: lepromin tests $(\geq 5 \mathrm{~mm}) ; \mathrm{LTT}(\mathrm{SI} \geq 3) ; \operatorname{IFN} \gamma(\geq 40 \mathrm{U} / \mathrm{ml}) ; \operatorname{IgM}$ anti-PGL-l (OD $\geq 0 \cdot 27)$.

and $12(63 \cdot 2 \%)$ had multiple lesions. When results are expressed as the percentage of patients that responded to the lepromin test with an induration $\geq 3 \mathrm{~mm}, 91 \cdot 7 \%$ of the patients showed a positive reaction. Again, no significative relationship was noted between the positivity in the lepromin test and the number of skin lesions (Table 1).

\section{Lymphoproliferation test (LTT)}

Among the 47 patients whose lymphocytes were submitted to LTT, 27 (57.4\%) showed positive results $(\mathrm{SI} \geq 3.0$ ). As shown in Figure 2, no significative correlation was observed between the positive lymphoproliferative test and the number of skin lesions, but a significative relationship was shown between LTT and the extent of nerve involvement $(P<0.05)$. Actually, $75 \%$ of the patients unresponsive to $M$. leprae in the LTT presented only one affected peripheral nerve or none at all (Table 1). Patients with positive LTT were equally distributed in relation to the number of skin lesions and/ or to the number of affected nerves. Among the 27 patients with positive LTT, 13 patients $(48 \cdot 1 \%)$ also had positive lepromin skin tests. In addition, 15 of the 20 patients with negative LTT were negative in the lepromin test as well. There was $59 \cdot 6 \%$ agreement between these two immunological tests. 
Table 1. Relationship among immunological tests and the number of cutaneous lesions, and among immunological tests and the number of affected nerves, in BT patients. Number of tested patients was 48 for lepromin tests; 47 for LTT; 18 for IFN $\gamma$ and 21 for PGL-I

\begin{tabular}{|c|c|c|c|c|c|c|c|c|}
\hline \multirow{3}{*}{$\begin{array}{l}\begin{array}{l}\text { Immunological } \\
\text { tests }\end{array} \\
\text { Lepromin }(\geq 5 \mathrm{~mm})\end{array}$} & \multicolumn{4}{|c|}{ Number of skin lesions } & \multicolumn{4}{|c|}{ Number of affected nerves } \\
\hline & & 1 & & + than 1 & & -1 & & han 1 \\
\hline & 7 & $(36 \cdot 8 \%)$ & 12 & $(63 \cdot 2 \%)$ & 10 & $(52 \cdot 6 \%)$ & 9 & $(47 \cdot 4 \%)$ \\
\hline Lepromin $(<5 \mathrm{~mm})$ & 17 & $(58.6 \%)$ & 12 & $(41 \cdot 4 \%)$ & 18 & $(62 \cdot 1 \%)$ & 11 & $(37 \cdot 9 \%)$ \\
\hline Lepromin $(\geq 3 \mathrm{~mm})$ & 22 & $(50 \%)$ & 22 & $(50 \%)$ & 25 & $(56.8 \%)$ & 19 & $(43 \cdot 2 \%)$ \\
\hline Lepromin $(<3 \mathrm{~mm})$ & 2 & $(50 \%)$ & 2 & $(50 \%)$ & 3 & $(75 \%)$ & 1 & $(25 \%)$ \\
\hline $\operatorname{LTT}(+)$ & 15 & $(55 \cdot 6 \%)$ & 12 & $(44 \cdot 4 \%)$ & 12 & $(44 \cdot 4 \%)$ & 15 & $(55 \cdot 6 \%)$ \\
\hline LTT $(-)$ & 8 & $(40 \%)$ & 12 & $(60 \%)$ & 15 & $(75 \%)$ & 5 & $(25 \%)$ \\
\hline $\operatorname{IFN} \gamma(+)$ & 4 & $(100 \%)$ & 0 & & 1 & $(25 \%)$ & 3 & $(75 \%)$ \\
\hline $\operatorname{IFN} \gamma(-)$ & 6 & $(42.9 \%)$ & 8 & $(57 \cdot 1 \%)$ & 7 & $(50 \%)$ & 7 & $(50 \%)$ \\
\hline PGL-I (+) & 1 & $(50 \%)$ & 1 & $(50 \%)$ & 1 & $(50 \%)$ & 1 & $(50 \%)$ \\
\hline PGL-I (-) & 10 & $(52.6 \%)$ & 9 & $(47 \cdot 4 \%)$ & 14 & $(73 \cdot 7 \%)$ & 5 & $(26.3 \%)$ \\
\hline
\end{tabular}

\section{Inteferon-gamma (IFN $\gamma)$ assay}

When patients' blood $(n=18)$ was tested for the release of IFN $\gamma$ into culture supernatants, only four individuals $(22 \cdot 2 \%)$ were found to be positive. These four patients had only one skin lesion $(P<0.05)$ (Figure 2(A)), but three of them had more than one affected nerve (Figure 2(B)). On the other hand, only 6 IFN $\gamma$ negative patients $(42 \cdot 8 \%)$ presented a single skin leprosy lesion. Two out of the four IFN $\gamma$ positive patients $(50 \%)$ showed a positive lepromin reaction. In addition, eight out of 14 individuals $(57 \cdot 1 \%)$ with negative IFN $\gamma$ were also negative in the lepromin test. There was an agreement of $55.5 \%$ between these two tests. All four patients with positive IFN $\gamma$ were positive in the LTT. Of the 14 patients found to be negative in the IFN $\gamma$ assay, six $(42.9 \%)$ were also negative in the LTT $(55 \cdot 5 \%$ concordance).

\section{PGL-1 Elisa test}

Twenty-one patients had their sera submitted to Elisa for detection of anti-PGL-1 IgM antibodies. Nineteen were negative $(90 \cdot 5 \%)$. No correlation was noted when compared to skin and nerve involvement. The two patients $(9.5 \%)$ who showed positive results were lepromin negative, and only one had positive LTT. The low levels of anti-PGL-1 antibodies observed among these patients confirmed their tuberculoid background including those with multiple lesions.

\section{REACTIONAL EPISODES}

A total of 6 patients $(12.5 \%)$ developed reaction. Of the four patients who developed reversal reaction (RR), two showed no nerve involvement, and two had multiple nerves affected. All patients presented more than one leprosy lesion. Two patients developed isolated neuritic episodes. Both had more than one affected nerve, but only one presented multiple cutaneous lesions. The fact that blood samples were collected from these patients during the initial examination and not during the reactional episode made the correlation between reaction and immunological tests unreliable. 
HISTOPATHOLOGY

Histological analysis confirmed the diagnosis of borderline-tuberculoid leprosy in all cases.

\section{Discussion}

Forty-eight borderline-tuberculoid patients were included in this study. Besides all clinical characteristics of the resistant form of the disease delineated in this study, only $50 \%$ of the patients presented single skin lesion and $58 \%$ had none or only one affected nerve. Interestingly, we have observed that patients with positive lepromin skin tests had more skin lesions, when compared to patients with negative lepromin tests. Although not statistically significant, these data emphasize the current interpretation that the lepromin test is evidence of delayed type hypersensitivity (DTH) and does not necessarily reflect protection in leprosy. On the other hand, no significative correlation was observed between the lymphoproliferative response and the number of skin lesions, but patients unresponsive to LTT had less nerve involvement, which may reflect a hypersensitivity effect. IFN $\gamma$ is perhaps the key cytokine responsible for the activation of the oxidative and anti-microbial activity of human macrophages. ${ }^{9}$ The finding that all responder BT patients who released high IFN $\gamma$ levels in PBMC culture supernatant had only one skin lesion $(P<0 \cdot 05)$, attributes an important role to IFN $\gamma$ in restraining the spread of infection. IFN $\gamma$ is a key component in determining the type of effector function that eventually develops during the course of an immune response. There is considerable evidence that the presence of IFN $\gamma$ in the milieu induces inhibition of the expansion of Th2-like cells. In addition, during $M$. leprae infection, a protective response is sometimes observed in the absence of granuloma formation, such as in the indeterminate form of the disease, which in some patients is supposed to be self-healing. All these data suggest that protective immune response and DTH are not the same phenomenon, in spite of being frequently simultaneous. ${ }^{7}$ However, $75 \%$ of the high responder patients in the IFN $\gamma$ assay had more nerves damaged when compared to the nonresponder ones. These results have very important implications and strongly suggest that nerve damage may represent a hypersensitivity phenomenon following cell-mediated immunity against the pathogen. The potential pathological effects of IFN $\gamma$ can be related to its ability to synergize with inflammatory cytokines, such as TNF $\alpha$, IL- $1 \beta$ and others. Previous studies ${ }^{2}$ have demonstrated that IFN $\gamma$ acting synergistically with inflammatory cytokines is able to induce or to increase the expression of adhesion molecules on endothelial cells and keratinocytes that affects directly the type and the amount of leukocytes attracted to the site of inflammation. Recently, a higher expression of TNF $\alpha$ mRNA as well as TNF $\alpha$ protein was demonstrated in the nerves and skin of borderline patients with RR. ${ }^{6}$ Although in some patients, absence of or low IFN $\gamma$ production was detected in vitro, the immunohistochemical findings suggest that, at least in situ, levels of IFN $\gamma$ are sufficient to maintain the activation state (data not shown).

Six patients presented reactional episodes (12.5\%). All but one $(83 \cdot 3 \%)$ had more than one skin lesion. Correlation between the reactional features and the in vivo and in vitro immunological tests was not reliable. This may in part be explained by the fact 
that tests were performed at the diagnosis, which, for the most part, was quite distant from the reactional episode. Neuritis following multidrug therapy seems to occur inf requently in bacteriologically negative BT patients. Only two patients $(4 \%)$ presented neuritis after MDT.

In a previous report, ${ }^{12}$ it was found that seropositivity to anti-PGL-1 antibodies was associated with subsequent manifestation of RR. This association was strongest in patients who were both anti-PGL-1 antibody and lepromin positive. However, to our way of thinking, no correlation was noted between levels of anti-PGL-1 antibodies and development of reaction. The two patients who were anti-PGL-1 antibody seropositive were lepromin negative and were not included among the six individuals who developed reaction during the study.

The present study confirms previous reports indicating the role of IFN $\gamma$ in mediating resistance to mycobacterial infection. ${ }^{4,5}$ However, other mechanisms might be involved in restricting bacterial growth in borderline-tuberculoid patients.

\section{Acknowledgments}

We would like to thank to A. R. Moura and C. G. Rocha and E. R. Leite for assisting us with the computer work and for typing the manuscript. Thanks are also due to Miguel Dummet and to Dr Saleg Eid for substantial help in the statistical analyses.

\section{References}

${ }^{1}$ Bjune G, Barnetson RSC, Ridley DS, Kronvall G. Lymphocyte transformation test in leprosy: Correlation of the response with inflammation of lesions. Clin Exp Immunol, 1976; 25: 85-94.

2 Barker JNWN, Sarma V, Mitra RS, Dixit VM, Nickoloff BJ. Marked synergism between tumor necrosis factor- $\alpha$ and interferon- $\gamma$ regulation of keratinocyte-derived adhesion molecules and chemotactic factors. $J$ Clin Invest, 1990; 85: 605-8.

3 van Brakel WH, Soldenhoff R, McDougall AC. The allocation of leprosy patients into paucibacillary and multibacillary groups for multidrug therapy, taking into account the number of body areas affected by skin, or skin and nerve lesions. Lepr Rev, 1992; 63: 231-246.

${ }^{4}$ Cooper AM, Dalton DK, Stewart TA, Griffin JP, Russell DG, Orme IM. Disseminated tuberculosis in interferon $\gamma$ gene-disrupted mice. $J$ Exp Med, 1993; 178: 2243-47

5 Flyn JAL, Chan J, Triebold KJ, Dalton DK, Stewart TA, Bloom BR. An essential role for interferon $\gamma$ in resistance to Mycobacterium tuberculosis inf ection. J Exp Med, 1993; 178: 2249-2254.

6 Khanolkar-Young S, Rayment N, Brickell PM, Katz DR, Vinayakumar S, Colston MJ, Lockwood DNJ. Tumour necrosis factor-alpha $(\mathrm{TNF} \alpha)$ synthesis is associated with the skin and peripheral nerve pathology of leprosy reversal reactions. Clin Exp Immunol, 1995; 99: 196-202.

7 Mitsuyama M, Nawamura I. Gamma interferon-producing ability as a possible marker for the protective T cells against Mycobacterium bovis BCG in mice. Paper presented at 26th Joint Conference on Tuberculosis and Leprosy, Seattle, 1991 (Abstract page 40-44 in "Abstracts").

8 Naranayan RB, Laal S, Sharma AK, Bhutani, LK, Nath I. Differences in predominant T cell phenotypes and distribution pattern in reactional lesions of tuberculoid and lepromatous leprosy. Clin Exp Immunol, 1984; 55: 623-8.

9 Nathan CF, Murray HW, Wiebe NW and Rubin BY. Identification of interferon $\gamma$ as the lymphokine that activates human macrophage oxidative metabolism and antimicrobial activity, $J$ Exp Med, 1983; 158: 67089.

10 Ramos T, Zalcberg-Quintana I, Appelberg R, Sarno EN, Silva MT. T-helper cell subpopulations and the immune spectrum of leprosy. Internat J Lepr, 1989; 57: 73-81.

11 Ridley DS and Jopling WH. Classification of leprosy according to immunity. A five-group system. Int $J$ Lepr, 1966; 34: 255. 
${ }^{12}$ Roche PW, Theuvenet JM, Britton WJ. Risk-factors for reversal reaction in borderline leprosy patients. Lancet, 1991; 338: 654-7.

${ }^{13}$ Saad MHF, Medeiros MA, Gallo MEN, Gontijo PP, Fonseca LS. IgM immunoglobulins reacting with the phenolic glycolipid-1 antigen from Mycobacterium leprae in sera of leprosy patients and their contacts $\mathrm{Mem}$ Inst Oswaldo Cruz, 1990; 85: 191-4.

${ }^{14}$ Sampaio EP, Moreira, AL, Kaplan G, Alvim MFS, Duppre NC, Miranda CF, Sarno EN. Mycobacterium leprae-induced interferon-gamma production by household contacts of leprosy patients: association with the development of active disease. J Infec Dis, 1991; 164: 990.

${ }^{15}$ Sarno EN, Espinsoa M, Sampaio EP, Vieira LMM, Figueiredo AA, Miranda CF, Esquenazi D, Salgado JLF, Nogueira N. Immunological responsiveness to $M$. leprae and BCG antigens in 98 leprosy patients and their household contacts. Braz J Med Biol Res, 1988; 21: 461.

16 Yamamura M, Uyemura K, Deans RJ, Weinberg K, Rea TH, Bloom BR, Modlin RL. Defining protective responses to pathogens: cytokine profiles in leprosy lesions. Science, 1991; 254: 277. 